The University of Maine

\title{
DigitalCommons@UMaine
}

Marine Sciences Faculty Scholarship

School of Marine Sciences

$12-1-2008$

\section{Field-Based Evaluations of Horizontal Flat-Plate Fish Screens}

B. P. Rose

M. G. Mesa

Gayle Barbin-Zydlewski

University of Maine - Main, gayle.zydlewski@umit.maine.edu

Follow this and additional works at: https://digitalcommons.library.umaine.edu/sms_facpub

\section{Repository Citation}

Rose, B. P.; Mesa, M. G.; and Barbin-Zydlewski, Gayle, "Field-Based Evaluations of Horizontal Flat-Plate Fish Screens" (2008). Marine Sciences Faculty Scholarship. 49.

https://digitalcommons.library.umaine.edu/sms_facpub/49 


\title{
Field-Based Evaluations of Horizontal Flat-Plate Fish Screens
}

\author{
Brien P. Rose and Matthew G. Mesa* \\ U.S. Geological Survey, Western Fisheries Research Center, Columbia River Research Laboratory, \\ 5501 Cook-Underwood Road, Cook, Washington 98605, USA \\ GAYLE BARBIN-ZydLEWSKI \\ School of Marine Sciences, University of Maine, 5741 Libby Hall, Orono, Maine 04469-5741, USA
}

\begin{abstract}
Diversions from streams are often screened to prevent the loss of or injury to fish. Hydraulic criteria meant to protect fish that encounter screens have been developed, but primarily for screens that are vertical to the water flow rather than horizontal. For this reason, we measured selected hydraulic variables and released wild rainbow trout Oncorhynchus mykiss over two types of horizontal flat-plate fish screens in the field. Our goal was to assess the efficacy of these screens under a variety of conditions in the field and provide information that could be used to develop criteria for safe fish passage. We evaluated three different invertedweir screens over a range of stream $\left(0.24-1.77 \mathrm{~m}^{3} / \mathrm{s}\right)$ and diversion flows $\left(0.10-0.31 \mathrm{~m}^{3} / \mathrm{s}\right)$. Approach velocities (AVs) ranged from 3 to $8 \mathrm{~cm} / \mathrm{s}$ and sweeping velocities (SVs) from 69 to $143 \mathrm{~cm} / \mathrm{s}$. We also evaluated a simple backwatered screen over stream flows of $0.23-0.79 \mathrm{~m}^{3} / \mathrm{s}$ and diversion flows of $0.08-0.32$ $\mathrm{m}^{3} / \mathrm{s}$. The mean SVs for this screen ranged from 15 to $66 \mathrm{~cm} / \mathrm{s}$ and the mean AVs from 1 to $5 \mathrm{~cm} / \mathrm{s}$. The survival rates of fish held for $24 \mathrm{~h}$ after passage over these screens exceeded $98 \%$. Overall, the number of fish-screen contacts was low and the injuries related to passage were infrequent and consisted primarily of minor fin injuries. Our results indicate that screens of this type have great potential as safe and effective fish screens for small diversions. Care must be taken, however, to avoid operating conditions that produce shallow or no water over the screen surface, situations of high AVs and low SVs at backwatered screens, and situations producing a localized high AV with spiraling flow.
\end{abstract}

Diversions from natural or manmade waterways are common in the United States and are used for many purposes. For example, diversions from the Sacramento-San Joaquin Delta provide water for about 18 million people and about 1 million ha of farmland in California (Danley et al. 2002). Many diversions are screened with various devices meant to prevent fish and other aquatic life from becoming entrained, injured, or killed. However, many thousands of water diversions remain unscreened. Large irrigation systems have been identified as a contributing factor in the decline of salmonids over the past few decades (Nehlsen et al. 1991), and unscreened diversions are considered stressors on aquatic resources (Dadswell and Rulifson 1994; Kingsford 2000). Despite current Endangered Species Act listings of Pacific salmon Oncorhynchus spp., steelhead O. mykiss (anadromous rainbow trout), and bull trout Salvelinus confluentus and millions of dollars spent on screening (see McMichael et al. 2004), many diversions in the western USA remain unscreened or screened insufficiently.

Current and common screening technology (e.g.,

\footnotetext{
* Corresponding author: mmesa@usgs.gov
}

Received April 19, 2007; accepted April 18, 2008

Published online November 24, 2008 submersible traveling screens or rotary drum screens) and design criteria meant to protect fish (NOAA 2004) result in relatively expensive and high-maintenance facilities (McMichael et al. 2004). Despite state and federal cost-sharing programs, the high cost of these traditional fish screens deters the participation of private landowners with water rights, thus limiting the geographic expansion of fish screen installations throughout the western states. In recent years, however, many new screen designs have been developed that are potentially less expensive to install, offer simpler, more passive operation, and may have fewer detrimental effects on local fish communities. These new screen designs could offer attractive alternatives to private landowners interested in screening their diversions.

Horizontal flat-plate fish screens are an example of a recent alternative technology that could have lower installation and maintenance costs. Because of this, many screens of this type have been installed in the field. However, little is known about their hydraulic performance and biological impacts. Recently, Beyers and Bestgen (2001) used a working horizontal flatplate-screen model in a laboratory setting to investigate the effects of passage of bull trout over the screen. Also, Frizell and Mefford (2001) provided a detailed description of the hydraulic performance of this model. In a series of experiments under a variety of hydraulic 
conditions, Beyers and Bestgen (2001) reported few consistent negative effects on bull trout passing over the screen. Evaluating field sites with screens of this type would allow further verification of their performance, enable comparisons with criteria for more traditional fish screens, and perhaps facilitate their installation.

Historically, the development of criteria for the installation and operation of fish screens has depended primarily on laboratory studies of the swimming capabilities of relevant species (mostly juvenile anadromous salmonids). Such criteria are regulated by NOAA (the National Oceanic and Atmospheric Administration)-Fisheries for new and existing traditional screen installations. The idea underlying such criteria is that designers, engineers, and biologists have assumed that if the swimming abilities of a fish are greater than the approach velocities (AVs; the velocity of water actually passing through the screen surface) of the withdrawal intake, then fish are protected (Clay 1995). However, some research shows that contacts with a screen and impingement can occur at AVs far below the swimming capabilities of fish (Hanson and Li 1978; Swanson et al. 1998), suggesting that the swimming performance approach to the development of criteria for screens may be inadequate. Recently, Swanson et al. (2004 and 2005) conducted extensive laboratory tests of traditional vertical screens to validate and improve NOAA-Fisheries criteria for Chinook salmon $O$. tshawytscha and delta smelt Hypomesus transpacificus. Although these studies provided recommendations that should improve the operational criteria and structural design of common fish screens, more work is needed on other types of screens to increase our understanding of their effects on aquatic resources.

The goal of our study was to evaluate the performance of some uniquely designed horizontal flat-plate fish screens at selected locations in the field. Our specific objectives were to (1) measure some hydraulic variables of screens in the field under a variety of discharge and withdrawal conditions and (2) determine the extent of delayed mortality and the number of times fish contacted or were impinged on the screen after they were experimentally passed over the surface of screens in the field. We also qualitatively assessed the extent and severity of injury to fish after they passed over the screens. Our results should be useful for the development of guidelines for future screen installations, and for development of specific hydraulic and biological performance criteria for flatplate screen designs already being used at water diversion structures.

\section{Study Sites}

We evaluated several previously established horizontal flat-plate fish screen installations in Oregon, which we selected based on the following criteria: (1) the installations were representative of horizontal flatplate technology, (2) there had been no previous assessments of these screens, (3) fish species of concern were located in the area, and (4) the sites had good access and offered potential for experimental manipulation. The study sites included the Smith and Cook screens on McKay Creek, the Rye Grass screen on Ochoco Creek, and a screen on the east canal of the Donner und Blitzen River in southeastern Oregon. McKay and Ochoco creeks are tributaries of the Crooked River near Prineville, Oregon.

The Smith, Cook, and Rye Grass screens were inverted-weir, horizontal flat-plate screens constructed of 91-cm steel pipe inverted upstream and cemented into the river bottom (Figure 1). Screen-to-weir ratios (the linear length of screen/linear length of the instream portion of the weir) were $23 \%$ for the Smith, $41 \%$ for the Cook, and $57 \%$ for the Rye Grass screens. These facilities had three (Smith), five (Cook), and seven (Rye Grass) screening panels. The panels were $61 \mathrm{~cm}$ long and $122 \mathrm{~cm}$ wide and were constructed of 0.175 $\mathrm{cm}$ profile bar screen positioned perpendicular to river flow. The screening panels had 17\% (Smith), 16\% (Cook), and 4\% (Rye Grass) gradients, and the head differentials were approximately 25,8 , and $38 \mathrm{~cm}$. All screens were equipped with a V-notch slot to facilitate fish passage that did not require fish to traverse the screen surface and to eliminate the potential dewatering of stream areas below the screens during extreme environmental conditions, such as severe drought. The bottom of this slot was positioned $25 \mathrm{~cm}$ above the downstream water at the Smith screen and below the downstream water at the Cook screen. The Rye Grass screen used a three-tier V-notch system with a maximum head differential between tiers of $18 \mathrm{~cm}$. The Rye Grass screen was equipped with a removable downstream weir that could be deployed to prevent dewatering of the screen at low flows.

The screen on the east canal of the Donner und Blitzen River (the Malheur screen; Figure 2) is located on the Malheur National Wildlife Refuge near Frenchglen, Oregon. This screen was a simple backwatered horizontal flat-plate fish screen constructed of $120-\mathrm{cm}-$ diameter steel pipe that was divided in half along its long axis with two profile bar screening panels $(120 \times$ $240 \mathrm{~cm}$ with $0.175-\mathrm{cm}$ mesh) oriented parallel to flow. This screen was also equipped with a V-notch slot to facilitate fish passage and eliminate the potential for downstream dewatering. Water level over the screen 

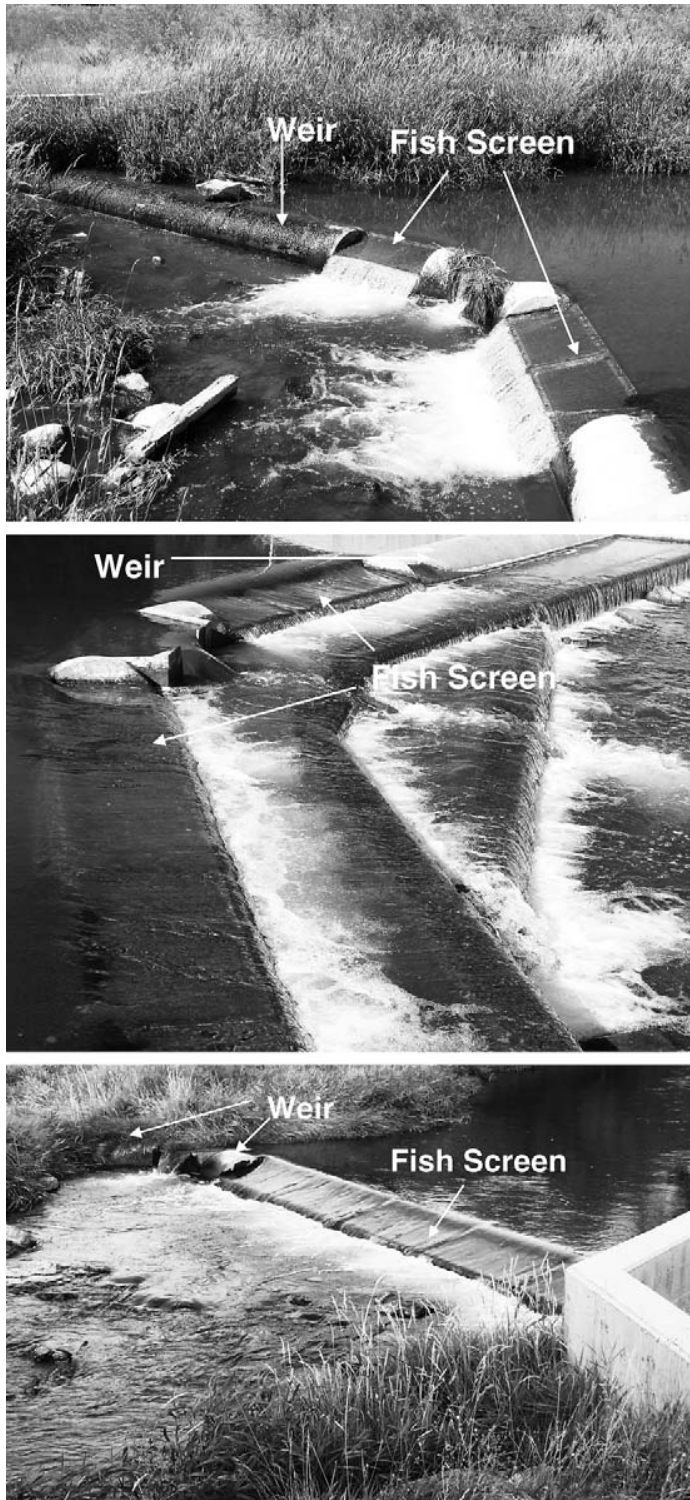

Figure 1.-Photographs of the Smith (top), Rye Grass (middle), and Cook (bottom) inverted-weir flat-plate fish screens located on McKay and Ochoco creeks near Prineville, Oregon. The screening panels are located in the cutout areas of steel pipe. Note the V-notch passage structure in the middle of each screen.

surface was controlled with an inverted rock weir positioned approximately $10 \mathrm{~m}$ downstream.

\section{Methods \\ Hydraulic Assessments}

At each screen and during different times of the year, we measured several hydraulic variables, including the

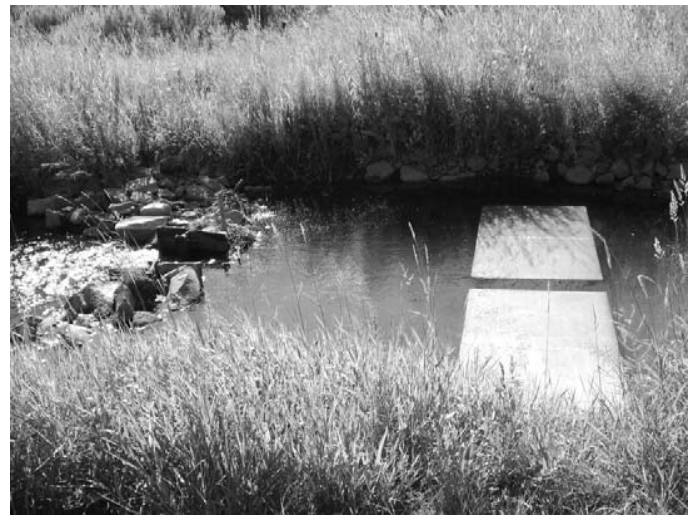

FIGURE 2.-Photograph of the backwatered horizontal flatplate fish screen (the Malheur screen) and the rock weir flow control structure located in the east canal of the Donner und Blitzen River, Oregon.

approach velocity, the sweeping velocity (SV; the velocity of the water flowing parallel to the screen surface), the water depth over the screen, river discharge, and diversion discharge. Approach velocities at all screens were estimated by dividing the effective screen area by the diversion rate (NOAA 2004). We chose this estimation method for the AVs (which assumes equal flow through all screening panels) because it required no special equipment, was the method most likely to be used in the field, could be easily done by irrigators or fishery managers that monitor the screens, and current technologies (e.g., micro acoustic Doppler velocimeters) were incapable of measuring three-dimensional flows in the shallow water depths that often occurred at these screens. Sweeping velocity measurements were generally taken over every $30-\mathrm{cm}^{2}$ section of screen surface area with a Marsh-McBirney electronic velocity meter. These measurements were collected at $7.6 \mathrm{~cm}$ above the screen surface or at 0.6 (depth) in shallower water. Water depth over the screen was measured using a depth gauge. Stream discharge was measured from the first suitable location upstream of the screen following the protocol of Gallagher and Stevenson (1999). When possible, diversion rates were estimated from screen outflow pipes and irrigation canals using the same protocol. We measured these variables at each site under natural conditions several times during the irrigation season. Sometimes, we experimentally manipulated diversion rates and depth of water at certain screens to assess hydraulic characteristics not observed during irrigation season. Such conditions could occur in the field and allowed us to evaluate the screens under the widest possible range of scenarios. During our assessments, screens were visually examined for 
"hot spots" (i.e., vortices, or spiraling downward flow through the screen). We used multiple linear regression analysis to assess the influence of several continuous and discrete variables (e.g., stream flow, screen gradient) on $\mathrm{AV}, \mathrm{SV}$, and water depth over the screen. We also compared our data with established NOAAFisheries screening criteria.

\section{Biological Assessments}

To evaluate the impact of screens in the field, we released fish over each screen and documented the number of times each fish contacted or was impinged on the screen during passage. We then qualitatively assessed the rate and severity of injuries sustained after passage and quantified the immediate and delayed (24h) mortality.

Fish collection.-The test fish were wild rainbow trout $O$. mykiss collected by means of a backpack electrofisher in stream sections adjacent to the fish screens. Fish were placed in 19-L buckets and transferred to live-cages near the screen for processing. When fish collection occurred away from the immediate area of the fish screen, fish were transferred to the screen site in an insulated plastic transport container $(100 \times 50 \times 60 \mathrm{~cm})$. Water temperature in all holding vessels was monitored and held at ambient during fish collections.

Processing fish before passage.-When all the fish for a test were at the screen site, they were anesthetized in either $50-\mathrm{mg} / \mathrm{L}$ solutions of buffered tricaine methanesulfonate (MS-222) or a solution of carbon dioxide (one tablet of Alka-Seltzer Gold per 2.5 L of water), measured for fork length (FL; mm), weighed (g), and given a comprehensive examination for injuries to the body. We modified criteria outlined by Beyers and Bestgen (2001) to assess fish condition before passage over a screen. The examinations included visual inspection of the skin (for abrasions, hemorrhages, or cuts), scales (percent of the body area descaled), fins (trace fin splits, fin splits, frayed fins, broken fins, and missing fins), and eyes (abrasions, exophthalmia, hemorrhages, and missing eyes). During some tests, and to facilitate individual identification, fish greater than $3.0 \mathrm{~g}$ were implanted with a $12-\mathrm{mm}$ passive integrated transponder (PIT) tag $(134.2 \mathrm{kHz})$ injected into the body cavity using a 12 gauge hypodermic needle, as described by Prentice et al. (1990). After all fish had been examined, they were randomly divided into two groups, treatment and control, for testing the next day. Age-classes of the test groups were estimated by length frequency analysis.

Experimental apparatus.-On the day of a test, a device to experimentally release fish over a screen was

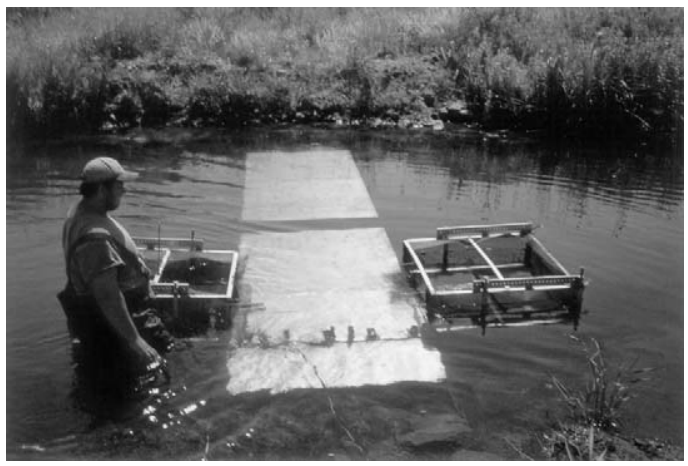

FIGURE 3.-Apparatus used to experimentally release juvenile rainbow trout over horizontal flat-plate fish screens in the field. The device is shown here attached to the Malheur fish screen. Each site required modifications to account for differences in water turbidity and the structural variations of the screens.

installed on the upstream and downstream ends of the screen (Figure 3). The device allowed fish to be released on the upstream side of the screen and recaptured on the downstream side. It consisted of two boxes, each $100 \times 100 \times 50 \mathrm{~cm}$ and constructed of an aluminum frame covered with $0.635-\mathrm{cm}$ plastic mesh webbing. One box was placed on the upstream side of the screen so the bottom was aligned with the screen surface. The second box was placed similarly on the downstream side of the screen and was equipped with a fyke net to facilitate quick capture of the fish after passage. Plexiglas or plastic mesh guide walls were installed perpendicular to the screen surface to ensure that fish traveled over the screen surface and were recaptured. The distance between guide walls was adjusted to facilitate visibility of our underwater camera observations (described below). After the device was in place, we measured the beforementioned hydraulic variables over the area of the screen that fish were to pass.

Releases of fish over the screens.-After the device was in place and the hydraulic variables were measured, groups of fish were released over the screen. We usually released fish under conditions where water was flowing straight and uniformly over the screen surface (axial flow). At the Malheur screen, we also conducted some releases over a section of screen that had hot spots (nonaxial flow, as explained above). Groups of 10-25 fish, either treatment or control, were removed from the holding cages and placed into the upstream box, one group at a time. Fish were allowed at least $10 \mathrm{~min}$ to volitionally leave the box and pass downstream over the screen. After $10 \mathrm{~min}$, we entered the stream, walked toward the device, and, if necessary, 
gently prodded the few remaining fish and forced them to move downstream. Usually, however, fish would move when we entered the stream. Experimental groups passed over the screen and were captured in the downstream box and immediately examined (see below). For control groups, a Plexiglas sheet was placed over the screen before passage, thus eliminating flow forces into the screen. These fish were used to assess the extent of mortality and injury that might be due to factors other than passage over the screen, such as capture, handling, and anesthesia. Releases of control and treatment groups were usually alternated until a combined sample of 35-70 fish had been tested. Several under and above water video cameras were used to record the behavior of fish during passage. All video tapes were reviewed at our laboratory, where we recorded the time required for each fish to pass over the screen, its general orientation to the current, how often it contacted the screen, how often it was impinged (i.e., stuck on the screen for $>1 \mathrm{~s}$ ), and its general depth of travel. Fish-screen contact and impingement rates were derived by dividing the total number of such occurrences by the number of fish viewed per release event.

Postpassage fish examinations and survival.-After passage, fish were immediately removed from the downstream box and placed in 19-L buckets. For each group, we recorded the number of fish that died immediately after passage. Live fish were anesthetized, measured, scanned for PIT tags, and examined for injuries using the criteria described above. Immediately after the postpassage examinations, fish were placed in live cages positioned in the stream and held for $24 \mathrm{~h}$ to assess the extent of delayed mortality. After $24 \mathrm{~h}$, we returned live fish to their original capture location.

Data analysis.-Fish that died immediately after passage or after $24 \mathrm{~h}$ were tallied. Using multiple regression analysis, we examined the relations between the number of times fish contacted the screen, fish size, $\mathrm{AV}, \mathrm{SV}$, water depth, stream flow, and diversion rate. For live fish we recorded whether it was injured (yes or no) after passage over the screen and what type of injuries it sustained. We accounted for the injuries fish had before release by either deducting the preexisting injury rate from the postpassage injury rate (untagged fish) or by counting the number of new injuries fish had after screen passage (PIT-tagged fish). Statistical significance was established at $\alpha=0.05$.

\section{Results}

\section{Hydraulic Assessments}

We evaluated inverted-weir screens over a range of stream flows $\left(0.24-1.77 \mathrm{~m}^{3} / \mathrm{s}\right)$ and diversion flows $\left(0.10-0.31 \mathrm{~m}^{3} / \mathrm{s}\right.$; Table 1$)$. The diversion rates comprised from $23 \%$ to $56 \%$ of the stream flow. Calculated AVs ranged from 3 to $8 \mathrm{~cm} / \mathrm{s}$; SVs ranged from 69 to $143 \mathrm{~cm} / \mathrm{s}$ and were slower along the upstream edge $(48-94 \mathrm{~cm} / \mathrm{s})$ and faster at the downstream edge of the screening panels (79-185 $\mathrm{cm} / \mathrm{s})$. Sweeping velocities were generally at least 10 times the AVs for most of the conditions we evaluated. The magnitude of increase in SV from the upstream to the downstream edge of a panel was greatest at the Smith and Cook screens (16-17\% gradient) and lowest at the Rye Grass screen (5\% gradient). The mean depth of the water over the screens ranged from 5 to $16 \mathrm{~cm}$ and was generally deeper at the upstream end (5-19 $\mathrm{cm})$ than the downstream end $(0-12 \mathrm{~cm})$. Mean SVs for all inverted-weir screens were directly related to stream discharge and inversely related to the screen : weir ratio $\left(R^{2}=0.84\right.$; Table 2). Also, the mean depths of water at the downstream side of the screen were related to several variables $\left(R^{2}=0.78\right.$; Table 2$)$. Screens with relatively high screen-to-weir ratios (the Cook and Rye Grass screens) had significantly lower mean SVs than the Smith screen (two sample $t$-test) even though the Smith screen was in an area with lower stream discharge.

We evaluated the Malheur screen over stream flows of $0.23-0.79 \mathrm{~m}^{3} / \mathrm{s}$ and diversion flows of $0.08-0.32$ $\mathrm{m}^{3} / \mathrm{s}$ (Table 1). The diversion rates comprised from $23 \%$ to $62 \%$ of the stream flow. The mean SVs for the Malheur screen ranged from 15 to $66 \mathrm{~cm} / \mathrm{s}$ and, in contrast to the inverted-weir screens, were faster along the upstream edge $(17-68 \mathrm{~cm} / \mathrm{s})$ and slower at downstream edge $(7-51 \mathrm{~cm} / \mathrm{s})$ of the screening panels. The calculated AVs over the entire screen area ranged from 1 to $5 \mathrm{~cm} / \mathrm{s}$. The mean depth of the water over the screen ranged from 6 to $34 \mathrm{~cm}$ and was slightly shallower at the upstream end $(7-32 \mathrm{~cm})$ than at the downstream end $(6-37 \mathrm{~cm})$. The mean $\mathrm{SVs}$ for the Malheur screen were directly related to stream discharge and inversely related to water depths, and the mean AVs were positively related to withdrawal discharge; the mean depth of water at the downstream side of the screen was related to stream discharge and SV (Table 2).

Hot spots were observed during our Malheur screen investigations when approach velocities exceeded 2 $\mathrm{cm} / \mathrm{s}$ (Figure 4). These hot spots covered approximately $20 \%$ of the total screen area and were located on the screening panel proximal to the diversion outflow.

\section{Survival}

For all of our tests, the survival rates of fish held for $24 \mathrm{~h}$ after passage were high. During releases of fish over the inverted-weir screens, survival rate was $99.9 \%$ for treatment fish and $99.1 \%$ for control fish. Treatment 
TABLE 1.-Summary of hydraulic conditions ( $Q=$ discharge, $\mathrm{SV}=$ sweeping velocity, and $\mathrm{AV}=$ calculated approach velocity) measured at two types of horizontal flat-plate fish screens tested at four field sites in 2004 and 2005; na = not available.

\begin{tabular}{|c|c|c|c|c|c|c|}
\hline Site & Date & $\underset{\left(\mathrm{m}^{3} / \mathrm{s}\right)}{\operatorname{Stream}} Q$ & $\begin{array}{l}\text { Diversion } Q \\
\left(\mathrm{~m}^{3} / \mathrm{s}\right)\end{array}$ & $\begin{array}{c}\mathrm{SV} \\
(\mathrm{cm} / \mathrm{s} ; \text { mean }[\mathrm{SD}])\end{array}$ & $\begin{array}{l}\mathrm{AV} \\
(\mathrm{cm} / \mathrm{s})\end{array}$ & $\begin{array}{c}\text { Depth } \\
(\mathrm{cm} ; \text { mean }[\mathrm{SD}])\end{array}$ \\
\hline \multicolumn{7}{|c|}{ Inverted weir } \\
\hline \multirow[t]{8}{*}{ Cook } & 4 Jun 2004 & 1.26 & na & $143(45)$ & na & $12(2)$ \\
\hline & 11 Aug 2004 & 0.47 & 0.20 & $104(24)$ & 5 & $5(3)$ \\
\hline & 13 Aug 2004 & 0.31 & 0.11 & $72(12)$ & 3 & $4(1)$ \\
\hline & 13 Aug 2004 & 0.31 & 0.16 & $70(4)$ & 4 & $5(4)$ \\
\hline & $6 \mathrm{Jul} 2005$ & 0.43 & 0.10 & $90(31)$ & 3 & $6(1)$ \\
\hline & $8 \mathrm{Jul} 2005$ & 0.42 & 0.16 & $88(18)$ & 4 & $5(2)$ \\
\hline & 13 Aug 2005 & 0.55 & na & $108(30)$ & na & $6(2)$ \\
\hline & 24 Aug 2005 & 0.39 & na & $112(24)$ & na & $5(2)$ \\
\hline \multirow[t]{12}{*}{ Rye Grass } & 17 Jun 2004 & 1.77 & 0.39 & $114(34)$ & 8 & $15(3)$ \\
\hline & 9 Jun 2005 & na & 0.20 & 99 (37) & 4 & $13(5)$ \\
\hline & 9 Jun 2005 & na & 0.26 & $93(46)$ & 5 & $10(5)$ \\
\hline & 9 Jun 2005 & na & 0.27 & $101(38)$ & 5 & $12(4)$ \\
\hline & $15 \mathrm{Jul} 2005$ & 0.54 & 0.30 & $78(26)$ & 6 & $6(9)$ \\
\hline & 17 Jul 2005 & 0.58 & 0.18 & $77(26)$ & 3 & 7 (3) \\
\hline & 17 Jul 2005 & 0.58 & 0.23 & $69(21)$ & 4 & $6(2)$ \\
\hline & 9 Aug 2005 & 0.55 & 0.31 & $73(20)$ & 6 & $5(2)$ \\
\hline & 11 Aug 2005 & 0.55 & 0.19 & $78(21)$ & 4 & $6(2)$ \\
\hline & 11 Aug 2005 & 0.55 & 0.27 & $85(21)$ & 5 & $6(2)$ \\
\hline & 11 Aug 2005 & 0.55 & 0.31 & $73(20)$ & na & $5(2)$ \\
\hline & 26 Aug 2005 & 0.62 & na & $85(18)$ & na & $8(9)$ \\
\hline \multirow[t]{5}{*}{ Smith } & 27 Jun 2004 & 0.47 & na & $132(32)$ & na & $9(3)$ \\
\hline & 9 Jun 2005 & na & na & $142(44)$ & na & $12(3)$ \\
\hline & 13 Jul 2005 & 0.33 & na & $117(38)$ & na & $7(3)$ \\
\hline & 12 Aug 2005 & 0.31 & na & 114 (37) & na & $6(2)$ \\
\hline & 24 Aug 2005 & 0.24 & na & $98(31)$ & na & $5(2)$ \\
\hline \multicolumn{7}{|c|}{ Backwatered } \\
\hline \multirow[t]{13}{*}{ Malheur } & $12 \mathrm{Jul} 2004$ & 0.79 & 0.17 & $29(8)$ & 3 & $34(2)$ \\
\hline & $14 \mathrm{Jul} 2004$ & 0.75 & 0.32 & $32(10)$ & 5 & $32(1)$ \\
\hline & 1 Aug 2004 & 0.33 & 0.13 & $15(6)$ & 2 & 31 (1) \\
\hline & 1 Aug 2004 & 0.33 & 0.17 & $15(12)$ & 3 & $30(1)$ \\
\hline & 3 Aug 2004 & 0.32 & na & $16(8)$ & 5 & $23(1)$ \\
\hline & 22 Jul 2005 & 0.23 & 0.11 & $22(7)$ & 2 & $12(1)$ \\
\hline & $24 \mathrm{Jul} 2005$ & 0.34 & 0.21 & $22(9)$ & 4 & $22(1)$ \\
\hline & $27 \mathrm{Jul} 2005$ & 0.30 & 0.10 & 47 (11) & 2 & $11(1)$ \\
\hline & $29 \mathrm{Jul} 2005$ & 0.32 & 0.11 & 49 (19) & 3 & $6(1)$ \\
\hline & $16 \mathrm{Jul} 2004$ & 0.61 & 0.14 & $57(8)$ & 2 & $18(1)$ \\
\hline & $18 \mathrm{Jul} 2004$ & 0.69 & 0.21 & $66(8)$ & 4 & $16(1)$ \\
\hline & $28 \mathrm{Jul} 2004$ & na & 0.08 & 52 (19) & 1 & $12(1)$ \\
\hline & $30 \mathrm{Jul} 2004$ & 0.46 & 0.19 & $57(24)$ & 3 & $10(1)$ \\
\hline
\end{tabular}

fish released over the Malheur screen showed 98\% (those released over hot spots) to $99 \%$ (those released over axial flow conditions) survival; control fish experienced $100 \%$ survival. Only 1 of more than 1,400 fish released died immediately after passage.

\section{Fish-Screen Contacts and Impingements}

The hydraulic conditions present during our fish releases generally fell within the range of values presented above (Table 3). During our releases of fish over the inverted-weir screens, the number of times that fish contacted the screen was higher during low-water conditions and for age-1 and older fishes (Table 3). During two evaluations at the Cook screen, very shallow water caused all fish to contact the screen. All contacts with the screen were of very short duration and no fish became impinged on the inverted-weir screens. The number of times that fish contacted an inverted-weir screen was inversely related to water depth over the screen (Figure 5) and not related to any other variable we examined. The time required for fish to travel over the screen was always $1 \mathrm{~s}$ or less, and fish generally traveled no more than $8 \mathrm{~cm}$ above the screen surface.

When fish were released over the Malheur screen under axial flow conditions, the number of contacts with or impingements on the screen was low $(0.6 \pm$ 0.7 [mean $\pm \mathrm{SD}$ ]; Table 4). When fish were released over hot spots, the number of times that fish contacted the screen increased significantly relative to axial flow conditions $(3.0 \pm 1.8 ; t$-test: $P<0.001)$. Under axial flow conditions, the number of times that fish contacted the screen was positively related to the AV (Figure 6). The number of times fish contacted the 
TABLE 2.-General linear models of the hydraulic variables measured in the field for two styles of horizontal flat-plate fish screens. All coefficients are significant $(P<0.05)$ unless specifically noted. Abbreviations are as follows: $\mathrm{AV}=$ approach velocity $(\mathrm{cm} / \mathrm{s}), \mathrm{SV}=$ sweeping velocity $(\mathrm{cm} / \mathrm{s}), Z$ $=$ depth of water over screen $(\mathrm{cm}), \mathrm{SQ}=$ stream discharge $\left(\mathrm{m}^{3} /\right.$ $\mathrm{s}), \mathrm{WQ}=$ withdrawal discharge $\left(\mathrm{m}^{3} / \mathrm{s}\right), \mathrm{SW}=$ screen length/ weir length (100), $G=$ screen gradient $(\%)$, and SEE = standard error of the estimate.

\begin{tabular}{lc}
\hline \multicolumn{1}{c}{ Type } & Equations \\
\hline \multirow{2}{*}{ Inverted-weir screens } \\
& $Z=9.29+9.67(\mathrm{SQ})-6.91\left(\mathrm{WQ}^{a}\right)$ \\
& $-0.12(\mathrm{SW})-0.16(G)$ \\
Approach velocity & $N=18, R^{2}=0.78, \mathrm{SEE}=0.60$ \\
& $\mathrm{AV}=-4.21+18.65(\mathrm{WQ})+0.07(\mathrm{SW})$ \\
& $\quad+0.16(G)$ \\
Sweeping velocity & $N=18, R^{2}=0.94, \mathrm{SEE}=0.41$ \\
& $\mathrm{SV}=118.33-2.03(\mathrm{SW})+133.87(\mathrm{SQ})$ \\
& $N=18, R^{2}=0.84, \mathrm{SEE}=8.24$ \\
Depths & Backwatered screen \\
& $\mathrm{Z}=20.80+37.70(\mathrm{SQ})-0.49(\mathrm{SV})$ \\
Approach velocity & $N=10, R^{2}=0.86, \mathrm{SEE}=3.79$ \\
& $\mathrm{AV}=14.25(\mathrm{WQ})$ \\
Sweeping velocity & $N=10, r^{2}=0.81, \mathrm{SEE}=0.47$ \\
& $\mathrm{SV}=70.82(\mathrm{SQ})-1.76(\mathrm{Z})$ \\
& $N=10, R^{2}=0.85, \mathrm{SEE}=7.19$ \\
\hline
\end{tabular}

${ }^{a} P=0.06$.

screen decreased and fish impingements were eliminated when SVs exceeded $20 \mathrm{~cm} / \mathrm{s}$ and AVs were $4 \mathrm{~cm} /$ $\mathrm{s}$ or less (i.e., when the SV : AV ratio was $>5$ ). The time required for fish to travel over the screen generally decreased with increased SV, and fish generally traveled within $8 \mathrm{~cm}$ of the screen surface.

\section{Injuries}

Detection of injuries in our fish solely due to screen passage was difficult because fish had natural injuries and incurred more injuries during capture, handling, and holding. Thus, injuries that fish had before passage over the screens were recorded and subtracted from our experimental groups before analysis. Overall, the postpassage injury rate incurred over the inverted-weir screens ranged from $0 \%$ to $18 \%$ (mean $=9.3 \%$ ), depending on test group. However, the injury rates of control fish ranged from $9 \%$ to $28 \%$ (mean $=17 \%$ ), indicating that factors other than screen passage contributed to injuries. For all fish, injuries consisted primarily of minor fin splits. Severe injuries were nonexistent. On two occasions when we released PITtagged fish, the injury rates for treatment fish were $79 \%$ and $83 \%$ and for control fish were $69 \%$ and $85 \%$. These rates were substantially higher than those from our batch releases because we were able to assess injuries on an individual fish basis. The conclusion that injuries were often due to factors other than screen passage still holds.

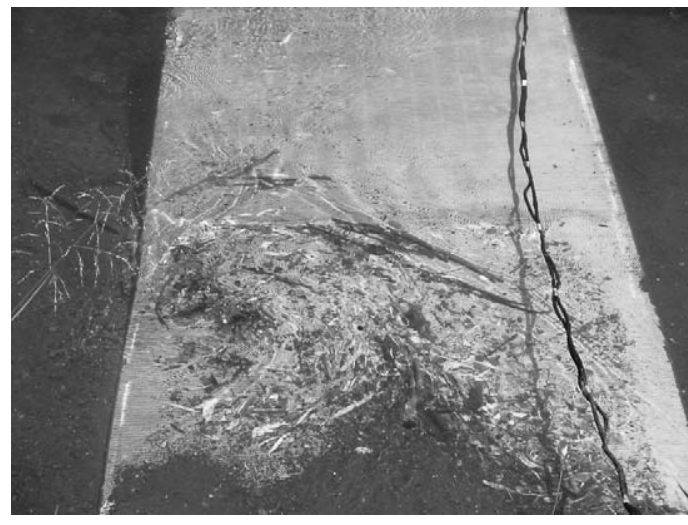

FIGURE 4.-Photograph of a localized area of high approach velocity with nonaxial or spiraling flow (a "hot spot") on the Malheur fish screen.

At the Malheur screen, injuries were more common when AVs were $4 \mathrm{~cm} / \mathrm{s}$ or more. Overall, under axial flow conditions, the injury rate of treatment fish ranged from $9 \%$ to $34 \%$ (mean $=20 \%$ ), whereas rates of control fish ranged from $9 \%$ to $24 \%$ (mean $=17 \%$ ). Again, all of these injuries were minor fin splits. For our releases of fish over hot spots, the injury rate of treatment fish ranged from $17 \%$ to $31 \%$ (mean $22 \%$ ), and the rates for control fish ranged from $13 \%$ to $18 \%$ $($ mean $=16 \%)$. The injuries again consisted of fin splits, sometimes of a more severe nature.

\section{Discussion}

Our results indicate that horizontal flat-plate screens of the types we tested have great potential as safe and effective fish screens for irrigation and other diversions. The designs were relatively simple, had no moving parts, and had SVs and AVs under a variety of hydraulic conditions that rarely injured or killed fish after passage and allowed easy maintenance and cleaning. The screen structures were relatively inexpensive to install compared with drum or other mechanically operated screens and can be designed for a variety of diversion rates. Thus, these horizontal flat-plate screens offer private landowners and irrigators a low cost, effective alternative for screening diversions that we found to cause minimal harm to fish. Other studies evaluated various designs of vertically oriented screens and reported results similar to ours (e.g., Danley et al. 2002; Zydlewski and Johnson 2002; Nobriga et al. 2004).

Despite the potential advantages of horizontal flatplate screens for protecting fish populations, there are several things to consider when interpreting our results. First, because our experiments were conducted in the 
TABLE 3.-Hydraulic conditions (AV = calculated approach velocity, $\mathrm{SV}=$ sweeping velocity, and $Z=$ water depth over the screen) and average number of fish contacts with the screen for two ages of juvenile rainbow trout that were experimentally released over inverted-weir fish screens during 2004 and 2005. Sweeping velocities in bold italics denote tests with low water depth at the rear of the screen. Contacts per fish were derived by dividing the total number of times that fish touched the screen by the number of fish viewed on video tapes. No fish were impinged on the inverted-weir screens; na = not available.

\begin{tabular}{|c|c|c|c|c|c|c|}
\hline Site & $\mathrm{AV}(\mathrm{cm} / \mathrm{s})$ & $\mathrm{SV}(\mathrm{cm} / \mathrm{s})$ & $Z(\mathrm{~cm})$ & $\begin{array}{c}\text { Age of } \\
\text { fish tested }\end{array}$ & $\begin{array}{l}\text { Number of } \\
\text { fish released }\end{array}$ & $\begin{array}{l}\text { Contacts } \\
\text { per fish }\end{array}$ \\
\hline \multirow[t]{6}{*}{ Cook } & 3 & 91 & 4 & 1 & 26 & 1.00 \\
\hline & 4 & 97 & 4 & 1 & 31 & 1.00 \\
\hline & 5 & 95 & 4 & 1 & 30 & 1.00 \\
\hline & 3 & 66 & 4 & 0 & 50 & 1.00 \\
\hline & 4 & 68 & 3 & 0 & 49 & 1.00 \\
\hline & 5 & 104 & 4 & 0 & 47 & 1.00 \\
\hline \multicolumn{7}{|c|}{ Rye Grass } \\
\hline & 8 & 136 & 12 & 1 & 77 & 0.17 \\
\hline & 3 & 79 & 8 & 1 & 39 & 0.46 \\
\hline & 4 & 82 & 8 & 1 & 38 & 0.53 \\
\hline & 6 & 99 & 8 & 1 & 30 & 0.35 \\
\hline & 4 & 78 & 7 & 0 & 44 & 0.24 \\
\hline & 5 & 85 & 7 & 0 & 43 & 0.20 \\
\hline & 6 & 81 & 7 & 0 & 52 & 0.15 \\
\hline & na & 61 & 3 & 0 & 39 & na \\
\hline \multicolumn{7}{|l|}{ Smith } \\
\hline & na & 128 & 6 & 1 & 40 & 0.39 \\
\hline
\end{tabular}

\footnotetext{
${ }^{a}$ Because of shallow water across the Cook screen, all fish were in constant contact with the screen during their traverse, making it impossible to enumerate more than or less than one contact for each fish tested.
}

field, we were unable to evaluate all possible hydraulic conditions on screen performance, fish-screen contacts, injury, and mortality. Basically, we had no control over stream flows and only minor control over diversion rates, so we often evaluated what nature and the irrigators provided at the time. Although we believe our evaluations were realistic because they encompassed typical irrigation scenarios, there may be other flow conditions we missed that are relevant to fish passage and safety. Second, our calculated values of AV, which resulted in an average value over the surface area of the screen, may not be representative of what the fish actually experience. Ancillary data that we collected using an acoustic Doppler velocimeter showed that AVs can vary over the screen surface area, but such devices are expensive, not always available, require detailed deployment methods to ensure accurate and precise data collection, and have limited use in some field situations. Although calculating a single AV for an entire screen may not represent the true hydraulic conditions at fine spatial scales over the screen surface, it is a practical and easy method to use in field situations. Third, only one species of fish was tested for the screen evaluations, and our results may not be applicable to other species. The juvenile, wild rainbow trout we used were probably good surrogates for other salmonids of similar size. Extrapolation of our results to other fishes, such as juvenile lampreys or endangered suckers in the Klamath basin, seems inappropriate and would require further testing. Finally, there are many design variations within the category of horizontal flat-plate screens and our tests represented only some of these. Evaluating screens with different screen materials (e.g., perforated-plate versus vertical-bar screens), screen panel angles and sizes, weir configurations, and other design elements would provide a more thorough understanding of flatplate screens in general.

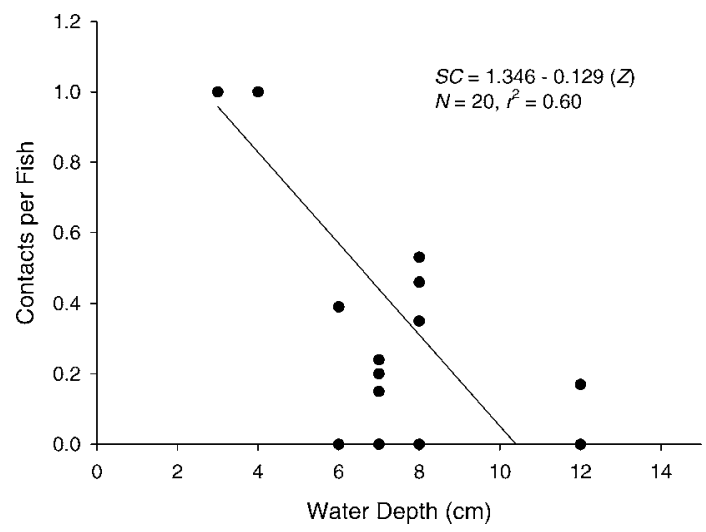

FIGURE 5.-Relationship between water depth $(Z)$ and screen contact rate (SC) by juvenile rainbow trout released over inverted-weir horizontal flat-plate fish screens. Contacts per fish were derived by dividing the total number of times that fish touched the screen by the number of fish viewed on video tapes. 
TABLE 4.- Hydraulic conditions (AV = approach velocity, SV = mean sweeping velocity, and $Z=$ water depth over the screen), average number of fish contacts with the screen, and impingement rates of subyearling rainbow trout that were experimentally released over the Malheur fish screen during 2004 and 2005. Contacts per fish were derived by dividing the total number of times that fish touched the screen by the number of fish viewed on video tapes; values exceeding one indicate fish contacting the screen several times.

\begin{tabular}{ccccccc}
\hline Flow & AV $(\mathrm{cm} / \mathrm{s})$ & $\mathrm{SV}(\mathrm{cm} / \mathrm{s})$ & $Z(\mathrm{~cm})$ & $\begin{array}{c}\text { Number of } \\
\text { fish released }\end{array}$ & $\begin{array}{c}\text { Contacts } \\
\text { per fish }\end{array}$ & $\begin{array}{c}\text { Impingements } \\
\text { per fish }\end{array}$ \\
\hline \multirow{2}{*}{ Axial } & 2 & 15 & 34 & 35 & 0.74 & 0.00 \\
& 3 & 13 & 31 & 38 & 0.65 & 0.03 \\
& 4 & 17 & 34 & 39 & 0.85 & 0.09 \\
& 5 & 21 & 30 & 40 & 1.88 & 0.03 \\
& 5 & 23 & 30 & 38 & 1.95 & 0.03 \\
& 2 & 26 & 13 & 21 & 0.20 & 0.00 \\
& 3 & 23 & 26 & 29 & 0.06 & 0.00 \\
& 4 & 23 & 24 & 32 & 0.04 & 0.00 \\
& 2 & 48 & 8 & 38 & 0.05 & 0.00 \\
& 3 & 46 & 5 & 33 & 0.63 & 0.00 \\
& 1 & 59 & 12 & 37 & 0.36 & 0.00 \\
& 3 & 63 & 11 & 32 & 0.22 & 0.00 \\
& 3 & 66 & 8 & 39 & 0.11 & 0.00 \\
& 3 & 22 & 34 & 21 & 0.04 & 0.00 \\
& 3 & 17 & 30 & 32 & 2.11 & 0.14 \\
& 5 & na & na & 35 & 4.17 & 0.26 \\
& 7 & 52 & 17 & 38 & 2.53 & 0.28 \\
& 2 & 58 & 15 & 43 & 4.58 & 0.21 \\
& 3 & 47 & 15 & 42 & 4.36 & 0.07 \\
\hline
\end{tabular}

\section{Hydraulic Characteristics of Screens}

Although detailed hydraulic assessments of the screens were beyond the scope of our study, there are some generalizations we can make relative to the two types of screens. The inverted-weir and simple, backwatered screens had variations in the design and structural components that created unique hydraulic properties at each. For example, the hydraulic properties of the inverted-weir screens were in large part created by using a weir that directed stream discharge over the screen surface area. These properties often met or exceeded fish protection criteria for vertical screens (NOAA 2004) and typically resulted in high SVs that were greater than AVs and quickly passed both fish and debris downstream. Also, we never observed hot spots over these screens. One potential drawback of this design, which we observed on several occasions, is that the water depth over the screens can be insufficient for fish passage. Shallow water over the screen surface was also a key factor contributing to higher fish-screen contacts. For example, during our 2005 investigations at the Rye Grass screen, the downstream third of the two screens nearest the diversion outflow were dewatered, potentially exposing fish to harmful situations. This dewatering was apparently caused by a combination of factors, including low stream discharge, high diversion rates, and excessive growth of aquatic vegetation near the screen that restricted stream flow near the dewatered area. Operators of such screens should be aware of factors that lead to dewatering of inverted-weir screens. The performance of these screens could be enhanced by decreasing the screen : weir ratio and by installing screens at steeper gradients relative to the stream surface-modifications that would help maintain high SVs and sufficient depths and decrease the risk of dewatering.

Unlike the inverted-weir design, the hydraulic conditions of the backwatered screen at Malheur were primarily controlled by a rock weir structure located

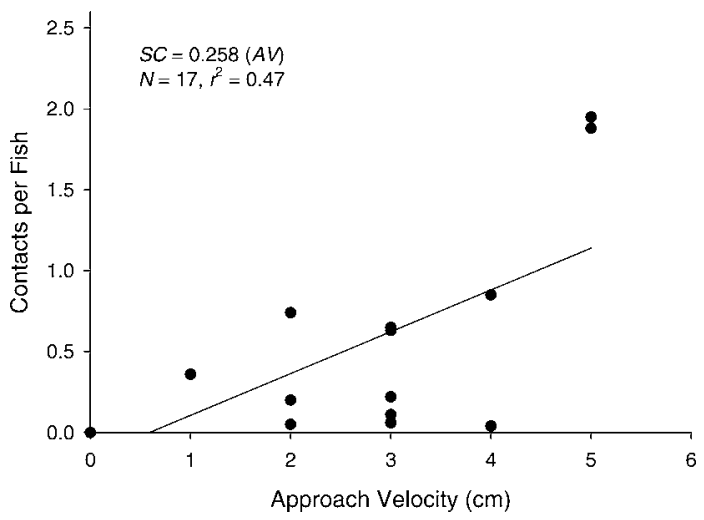

FIGURE 6.-Relationship between fish-screen contact rate (SC) and approach velocity (AV) for rainbow trout released over a backwatered horizontal flat-plate screen. Contacts per fish were derived by dividing the total number of times that fish touched the screen by the number of fish viewed on video tapes. 
downstream of the device. This structure could be used to manipulate water depth over the screen, thus providing some direct control over SVs. On average, our calculated AVs at the Malheur screen ranged from 1 to $5 \mathrm{~cm} / \mathrm{s}$, which were below current NOAAFisheries passive screen criteria $(6 \mathrm{~cm} / \mathrm{s})$. During the majority of the hydraulic conditions tested at the Malheur screen, we observed the presence of hot spots. These always occurred on the side of the screen proximal to the diversion. The exact cause of such hot spots is unknown but provides a subject for further study.

\section{Fish Passage over Screens}

We noted few negative effects of passing rainbow trout over these screens; the survival of fish was high, screen contacts were low, and injuries were infrequent and minor. Our results are similar to those in studies of bull trout passing over a laboratory model of a horizontal flat-plate screen (Beyers and Bestgen 2001), bull trout fry exposed to four types of diversion screens (Zydlewski and Johnson 2002), and juvenile Chinook salmon near a simulated screened water diversion (Swanson et al. 2004). Basically, the inverted-weir designs performed flawlessly, at least under the conditions we tested. For the Malheur screen, we noted that the rate of fish-screen contacts and minor injuries increased when AVs were relatively high and SVs were low. Minor increases in SV $(10 \mathrm{~cm} / \mathrm{s})$ reduced this effect and improved passage conditions. Because passage of fish over hot spots slightly increased their rates of mortality and injury, it seems prudent to identify the causes of such conditions and rectify them where possible.

The use of underwater video was superior to simply assessing injuries for the purpose of evaluating the effects of screen passage on fish condition if one accepts the notion that fish-screen contacts are a potentially harmful event. The videotapes provided clear evidence of the number of screen contacts and allowed us to assess the relative severity of such events. On the other hand, assessment of injuries of fish after passage over the screens was fraught with difficulties. Many of the fish used in our experiments had preexisting minor injuries, which were very timeconsuming to quantify and had to be taken into account before release. These injuries were influenced by capture, handling, and holding, which made it difficult to ascribe injuries solely to passage over a screen. Interestingly, the injuries sustained by fish after passage over the screens were not related to the number of screen contacts or impingements, which surprised us. For example, when we released fish over hot spots at the Malheur screen, we saw that they were experiencing relatively turbulent environments that caused high rates of screen contact and prolonged impingements. However, although we might interpret such conditions as unsuitable for safe fish passage, injury rates of fish during these tests were generally low. Similar results were reported by Swanson et al. (2004). In short, because examining fish for injury after passage over the screens was so time-consuming, had inherent sources of measurement error, and may not be indicative of poor passage conditions, we cannot recommend this method for future screen evaluations in the field. Other methods (e.g., dyes for assessing injuries to the skin or scales; Noga and Udomkusonsri 2002) may be simpler and easier on the fish, would work for large groups, and would probably be more effective.

Our video observations of the releases of fish over the inverted-weir screens indicated that many fish contacted the screen simply because there was shallow water over the screen surface. During shallow-water releases, fish often glided upright on their ventral side over the screen and, on occasion, with the dorsal portion of their body out of the water. The influence of shallow water on contact with the screen was greater for larger fish. Swanson et al. (2004) reported that injury rates of juvenile Chinook salmon were low and unrelated to contact rates after passage near a simulated screened water diversion. The high SVs associated with the inverted-weir screens effectively prevented any impingement of fish. At the Malheur screen, both $\mathrm{AVs}$ and SVs influenced the number of times fish contacted the screen. In contrast, Swanson et al. (2004) noted that contact rates of juvenile Chinook salmon passing near a vertically oriented screen were inversely related to SV and independent of $\mathrm{AV}$.

\section{Summary and Recommendations}

Overall, our field evaluations indicated that the passage of fish over two types of horizontal flat-plate screens under a wide variety of conditions was safe. The only conditions that have potential for concern were shallow or no water over the screen surface, situations of high AVs and low SVs at backwatered screens, and the presence of hot spots. For this reason, we recommend that screen managers operate their screens to avoid or minimize such conditions. The results from our hydraulic evaluations may be used as general guidelines, but screens in the field may have to be evaluated individually because design and environmental conditions can vary considerably. Future research on more detailed hydraulic evaluations of these screens would be useful for developing more specific operating criteria.

Current fish protection criteria (NOAA 2004) limit 
typical passive screen diversions to $0.03 \mathrm{~m}^{3} / \mathrm{s}$ (with a few exceptions) and set a maximum AV limit of $6 \mathrm{~cm} / \mathrm{s}$ for the protection of juvenile anadromous salmonids. These criteria, for the most part, would also work for horizontal flat-plate screens of the types we tested. The screens we evaluated safely and effectively diverted water up to and far beyond the $0.03-\mathrm{m}^{3} / \mathrm{s}$ criterion without affecting screen performance or increasing risk to fish passing over the screen. Although the AV limit of $6 \mathrm{~cm} / \mathrm{s}$ would provide adequate protection for fish at inverted-weir screens, it seems a little too high for use at backwatered screens. Until further information is available, we suggest that AVs of about $2-3 \mathrm{~cm} / \mathrm{s}$ should provide efficient and safe passage of fish over backwatered screens, provided that SVs can be maintained at $20 \mathrm{~cm} / \mathrm{s}$ or higher. Notably, Beyers and Bestgen (2001), in their laboratory study on bull trout, showed that when SVs were high $(>60 \mathrm{~cm} / \mathrm{s})$, fish could pass over a horizontal flat-plate fish screen at AVs of $15 \mathrm{~cm} / \mathrm{s}$ without consistent negative effects.

For horizontal flat-plate screens, SV and water depth over the screen are important factors to consider. For backwatered screens, our results suggest that SVs be maintained at $20 \mathrm{~cm} / \mathrm{s}$ or higher, which can be done by adjusting the downstream weir and lowering the water depth over the screen. Establishing a minimum depth requirement for backwatered screens will require more research. Under the conditions we tested, the SVs at the inverted-weir screens were high relative to those at the backwatered or traditional vertical fish screens and effective at passing fish; thus, it may not be necessary to establish SV criteria for these screens. The water depth necessary to safely pass fish over the invertedweir screen varies and depends largely on the size of fish and anticipated debris load. Our results suggest that water depths greater than $7 \mathrm{~cm}$ would probably provide adequate protection for anadromous salmonids up to about $200 \mathrm{~mm}$ fork length. Overall, development of specific criteria for flat-plate screens would benefit from further research, both in the laboratory and field.

\section{Acknowledgments}

This work could not have been completed without the help and support of numerous individuals and agencies. We thank Doug Young, Doug Dehart, Steve Duke, and Damien Miller of the U.S. Fish and Wildlife Service for providing helpful advice, review, and administration of our study; Mike Lambert, Ray Hartlerode, Tim Walters, and Brett Hodgson of the Oregon Department of Fish and Wildlife for technical assistance, equipment, and field help; Donna Stovall, Rick Roy, and the entire Malheur National Wildlife Refuge staff for their help in the field and useful suggestions; Russell Rodden and the Ochoco Irrigation
District staff for providing us with access to field sites and assisting with data collection; and all of the U.S. Geological Survey (USGS) employees (particularly Darren Pecora), contractors, and volunteers who assisted with field work and contributed many helpful suggestions. This research was funded by the USGS Science Support Program. Mention of trade names does not imply endorsement by the U.S. Government.

\section{References}

Beyers, D. W., and K. R. Bestgen. 2001. Bull trout performance in a horizontal flat-plate screen. Final report to the U.S. Bureau of Reclamation, Denver.

Clay, C. H. 1995. Design of fishways and other fish facilities. Lewis Publishers, Boca Raton, Florida.

Dadswell, M. J., and R. A. Rulifson. 1994. Microtidal estuaries: a region of collision between migratory marine animals and tidal power development. Biological Journal of the Linnaean Society 51:93-113.

Danley, M. L., S. D. Mayr, P. S. Young, and J. J. Cech, Jr. 2002. Swimming performance and physiological stress responses of splittail exposed to a fish screen. North American Journal of Fisheries Management 22:12411249.

Frizell, K., and B. Mefford. 2001. Hydraulic performance of a horizontal flat-plate screen. Final report to the U.S. Bureau of Reclamation, Denver.

Gallagher, A. S., and N. J. Stevenson. 1999. Streamflow. Pages 149-157 in M. B. Bain and N. J. Stevenson, editors. Aquatic habitat assessment: common methods. American Fisheries Society, Bethesda, Maryland.

Hanson, C. H., and H. W. Li. 1978. A research program to examine fish behavior in response to hydraulic flow fields: development of biological design criteria for proposed water diversions. Final completion report to the Office of Water Research and Technology, U.S. Department of the Interior, Sacramento, California.

Kingsford, R. T. 2000. Ecological impacts of dams, water diversions, and river management on floodplain wetlands in Australia. Australia Ecology 25:109-127.

McMichael, G. A., J. A. Vucelick, C. S. Abernathy, and D. A. Neitzel. 2004. Comparing fish screen performance to physical design criteria. Fisheries 29(7):10-16.

Nehlsen, W., J. E. Williams, and J. A. Lichatowich. 1991. Pacific salmon at the crossroads: stocks at risk from California, Oregon, Idaho, and Washington. Fisheries 16(2):4-21.

NOAA (National Oceanic and Atmospheric Administration). 2004. Draft anadromous salmonid passage facility guidelines and criteria. NOAA, Portland, Oregon.

Nobriga, M. L., Z. Matica, and Z. P. Hymanson. 2004. Evaluating entrainment vulnerability to agricultural irrigation diversions: a comparison among open-water fishes. Pages 281-295 in F. Feyrer, L. R. Brown, R. L. Brown, and J. J. Orsi, editors. Early life history of fishes in the San Francisco Estuary and watershed. American Fisheries Society, Symposium 39, Bethesda, Maryland.

Noga, E. J., and P. Udomkusonsri. 2002. Fluorescein: a rapid, sensitive, nonlethal method for detecting skin ulceration in fish. Veterinary Pathology 39:726-731. 
Prentice, E., T. Flagg, and C. S. McCutcheon. 1990. Feasibility of using passive integrated transponder (PIT) tags in salmonids. Pages 317-322 in N. C. Parker, A. E. Giorgi, R. C. Heidinger, D. B. Jester, Jr., E. D. Prince, and G. A. Wenam, editors. Fish-marking techniques. American Fisheries Society, Symposium 7, Bethesda, Maryland.

Swanson, C., P. S. Young, and J. J. Cech, Jr. 1998. Swimming performance of delta smelt: maximum performance and behavioral and kinematic limitations of swimming at submaximal velocities. Journal of Experimental Biology 201:333-345.

Swanson, C., P. S. Young, and J. J. Cech, Jr. 2004. Swimming in two vector flows: performance and behavior of juvenile Chinook salmon near a simulated screened water diversion. Transactions of the American Fisheries Society 133:265-278.

Swanson, C., P. S. Young, and J. J. Cech, Jr. 2005. Close encounters with a fish screen: integrating physiological and behavioral results to protect endangered species in exploited ecosystems. Transactions of the American Fisheries Society 134:1111-1123.

Zydlewski, G. B., and J. R. Johnson. 2002. Response of bull trout fry to four types of water diversion screens. North American Journal of Fisheries Management 22:12761282. 